\title{
Downregulation of RNF138 inhibits cellular proliferation, migration, invasion and EMT in glioma cells via suppression of the Erk signaling pathway
}

\author{
HAIBIN WU ${ }^{1 *}$, XUETAO LI ${ }^{1 *}$, MING FENG $^{1}$, LIN YAO $^{1}$, ZHITONG DENG $^{1}$, \\ GUOZHENG ZAO $^{1}$, YOUXIN ZHOU ${ }^{1}$, SANSONG CHEN ${ }^{2}$ and ZIWEI DU ${ }^{1}$ \\ ${ }^{1}$ Department of Neurosurgery \& Brain and Nerve Research Laboratory, The First Affiliated Hospital of \\ Soochow University, Suzhou, Jiangsu $215006 ;{ }^{2}$ Department of Neurosurgery, Yijishan Hospital, \\ The First Affiliated Hospital of Wannan Medical College, Wuhu, Anhui 241001, P.R. China
}

Received April 28, 2018; Accepted September 21, 2018

DOI: 10.3892/or.2018.6744

\begin{abstract}
Glioma is the most common adult malignant primary brain tumor; however, the effect of chemotherapy is often limited by drug-resistance and poor prognosis is common. Ring finger protein 138 (RNF138) belongs to the E3 ligase family, and has significantly higher expression level in glioma tissue than in noncancerous brain tissues. Epithelial-mesenchymal-transition (EMT) has a critical role in cancer invasion and metastasis, ultimately leading to increased cell motility and resistance to genotoxic agents. Extracellular-signal regulated kinase (Erk) pathways promote the growth of glioma cells and enhance tumor invasion, with a role in the progression of EMT. However, the association between RNF138 and human glioma progression remains poorly understood. Relatively little is known about the association between RNF138, Erk, and EMT in glioma progression. In the current study, experiments were performed to explore the potential roles and mechanisms of RNF138 in glioblastoma in vitro and in vivo. Glioma cell line proliferation, migration and invasion were inhibited by knockdown of RNF138 in vitro. By lowering the RNF138 expression, cleaved caspase 3 and E-cadherin were upregulated, while phospho-Erk1/2, vimentin, MMP2, HIF-1 $\alpha$ and VEGF were downregulated in U87 and U251 cells in vitro. In vivo findings revealed that the growth of U87 cell-transplanted tumors in nude mice was
\end{abstract}

Correspondence to: Dr Youxin Zhou, Department of Neurosurgery \& Brain and Nerve Research Laboratory, The First Affiliated Hospital of Soochow University, 188 Shizi Street, Suzhou, Jiangsu 215006, P.R. China

E-mail: zhouyouxin@suda.edu.cn

${ }^{*}$ Contributed equally

Key words: ring finger protein 138, proliferation, migration, invasion, epithelial-mesenchymal transition, extracellular signalregulated kinase, glioma inhibited in tumors with RNF138 knockdown. These findings suggested that downregulation of RNF138 inhibited glioma cell proliferation, migration, and invasion, and reversed EMT, potentially via Erk signaling pathway. Therefore, RNF138 may be a potential therapeutic target against glioma.

\section{Introduction}

Glioblastoma (GBM) is one of the most aggressive types of brain tumor. Despite great progress in the therapeutic strategies for GBM over the past few decades, the prognosis remains poor (1-4). The median overall survival is $\sim 14.6$ months from the time of diagnosis and the 5-year survival rates are $<9.8 \%$ following standard care $(5,6)$. With the continuing advances in molecular biology, gene therapy has become a focus for cancer treatment (7). Thus, deeper research and better understanding of the molecular mechanisms of glioma formation and progression is necessary to establish the diagnostic and therapeutic targets.

E3 ubiquitin-protein is a peptide ligase that have been identified as a bio-marker and therapeutic target of glioblastoma (8). Ring finger protein 138 (RNF138) is a member of the E3 ligase family, which contains an N-terminal Cys(3)-His-Cys(4) ring finger protein domain, three zinc-finger-like domains and a C-terminal ubiquitin-interacting motif (UIM) type (9). Our previous study confirmed that RNF138 expression was significantly increased in glioma tissues and in the glioma cell lines U87 and U251 compared with non-cancerous brain tissues by reverse transcription-quantitative polymerase chain reaction (RT-qPCR) (10). However, the mechanism of RNF138 in the progression of glioma has not been fully elucidated.

Epithelial-mesenchymal-transition (EMT) is a developmental process, where polarized epithelial cells undergo multiple biochemical changes and assume a mesenchymal phenotype (11). This subsequently increases the migratory capacity, invasiveness, resistance to apoptosis and expression of extracellular matrix components in cells (12-14). Tumor recurrence in glioma is partly attributed to the increased EMT, enhanced aggressive behavior and treatment resistance of the tumor cells $(15,16)$. The extracellular signal-regulated protein kinases (Erk) signaling 
pathways have been reported to have an important role in modulating cell invasion and progression of EMT. Thus, it is necessary to understand the role of Erk signaling pathways and RNF138 in the EMT process in human glioblastoma.

Therefore, the present study explored whether RNF138 has a role in the proliferation, migration and invasion of glioma. A lentiviral-mediated RNA interference (RNAi) system was used to explore the effect of RNF138 on the migration, proliferation of U87 and U251 cells in vitro. Furthermore, the possible mechanisms involved in this process were also investigated. The study suggested that RNF138 was important for the proliferation, migration and invasion of glioma cells. Downregulation of RNF138 inhibited the process of EMT by suppressing Erk signaling pathway in glioma.

\section{Materials and methods}

Cell lines. The cell lines U87 ATCC (glioblastoma cells of unknown origin) and U251 (astrocytoma) were purchased from the Cell Bank of Type Culture Collection of the Chinese Academy of Sciences (Shanghai, China). All cell lines were maintained in Dulbecco's modified Eagle's medium (DMEM; HyClone; GE Healthcare Life Sciences, Logan, UT, USA) supplemented with $100 \mathrm{U} / \mathrm{ml}$ of penicillin, $100 \mu \mathrm{g} / \mathrm{ml}$ of streptomycin and $10 \%$ fetal bovine serum (FBS; Gibco; Thermo Fisher Scientific, Inc., Waltham, MA, USA) at $37^{\circ} \mathrm{C}$ in a humidified atmosphere of $5 \% \mathrm{CO}_{2}$ in air.

RNF138 small interfering RNA (siRNA) lentiviral vectors. siRNAs sequences targeting human RNF138 gene were designed by Shanghai GenePharm Co., Ltd. (Shanghai, China). The selected template was 5'-CTGTAACAGTAATCACCTA-3'. Following confirmation by sequencing, the sequences were cloned into pGCSIL-green fluorescent protein (GFP; Shanghai GenePharm Co., Ltd., Shanghai, China) to generate the lentiviral vectors. The following sequences were used: RNF138, sense 5'-GATCCGGATCACTGTAACAGTAATCATTCA AGAGATGATTACTGTTACAGTGATCCTTTTTTG-3', antisense 5'-AATTCAAAAAAGGATCACTGTAACAGTAAT CATCTCTTGAATGATTACTGTTACAGTGATCCG-3'), NC, sense 5'-UUCUCCGAACGUGUCACGUTT-3' and antisense 5'-ACGUGACACGUUCGGAGAATT-3'. Lentiviral vectors construction and production were completed by Shanghai GenePharm Co., Ltd. The average titre of the lentiviral vectors was $\geq 5 \times 10^{8}$ transducing units $/ \mathrm{ml}$.

Cell cultures and lentivirus siRNA gene transduction. U87 and U251 cells in the exponential phase were resuspended in $0.25 \%$ trypsin. Cells were plated in 6-well plates $\left(5 \times 10^{4}\right.$ cells/well) until cell density reached $30 \%$ confluence. Then, according to the multiplicity of infection value (number of lentiviruses:number of cells), appropriate amount of lentiviruses were added to the cells. After $24 \mathrm{~h}$, the medium was replaced with fresh DMEM medium and incubated further for $48 \mathrm{~h}$. Then, cells were observed under a fluorescence inverted microscope and flow cytometry analysis was performed to detect for GFP expression.

RNA extraction RT-qPCR. Total RNA was extracted from U87 and $\mathrm{U} 251$ cell cultures after 5 days of transfection using TRIzol reagent (Invitrogen; Thermo Fisher Scientific, Inc.) according to the manufacturer's instructions. Concentration and purity of RNA were determined spectrophotometrically by measuring its optical density (absorbance 260/280 >2.0; absorbance 260/230 >1.8) using a NanoDrop ND-1000 (Thermo Fisher Scientific, Inc.). Total RNA (2 $\mu \mathrm{g})$ was used for RT in a $20 \mu \mathrm{l}$ reaction containing $10 \mathrm{U}$ M-MLV Reverse Transcriptase and $0.5 \mu \mathrm{g}$ oligo (dT) primer. Samples were incubated for $5 \mathrm{~min}$ at $25^{\circ} \mathrm{C}$ followed by $60 \mathrm{~min}$ at $42^{\circ} \mathrm{C}$ and the reaction was terminated by heating at $70^{\circ} \mathrm{C}$ for $5 \mathrm{~min}$. cDNA $(2 \mu \mathrm{l})$ was used for qPCR. The specific primer pairs used are as follows: RNF138, sense 5'-ATGTCCTATTTGTGTGTCTCTTCC-3', antisense 5'-GCAGTTTGGTATTGGGTTTCTTC-3'; product size was $144 \mathrm{bp}$. GAPDH was used as the internal control gene and the primer pairs used are as follows: Sense 5'-CAAGGT CATCCATGACAACTTTG-3', antisense 5'-GTCCACCAC CCTGTTGCTGTAG-3', product size was 496 bp. The number of cycles of PCR was optimized to ensure the product intensity to be within the linear phase of amplification. The PCR protocol consisted of an initial denaturation step at $95^{\circ} \mathrm{C}$ for 5 min, followed by 30 cycles of three-step program at $95^{\circ} \mathrm{C}$ for $30 \mathrm{sec}, 60^{\circ} \mathrm{C}$ for $30 \mathrm{sec}, 72^{\circ} \mathrm{C}$ for $30 \mathrm{sec}$, and a final extension step of $72^{\circ} \mathrm{C}$ for $10 \mathrm{~min}$ to amplify RNF138. The RNF138 and GAPDH genes were amplified with SYBR Master Mixture (Takara, Japan). Results are presented as quantitation cycle (Cq) values, and were defined as the PCR cycle quantification number at which an amplified product was first detected. The average $\mathrm{Cq}$ was calculated for RNF138 and GAPDH, and $2^{-\Delta \Delta \mathrm{Cq}}$ was determined as the mean of the triplicate $\mathrm{Cq}$ values for RNF138 minus the mean of the triplicate $\mathrm{Cq}$ values for GAPDH. The $2^{-\Delta \Delta \mathrm{Cq}}$ method (17) was used to analyze the relative changes in the gene expression.

Colony suppression assay. For colony formation assay, 200 cells/well were seeded into 6 -well plates for $48 \mathrm{~h}$ after transduction. Then the cells were cultured at $37^{\circ} \mathrm{C}$ in a $5 \%$ $\mathrm{CO}_{2}$ incubator with the medium changed every 2 days. On day 14 , the culture medium was removed, and the cells were washed twice with PBS. Subsequently, the colonies were fixed in $10 \%$ methanol at room temperature for $15 \mathrm{~min}$, stained with $1 \%$ crystal violet (Sigma-Aldrich; Merck KGaA, Darmstadt, Germany) at room temperature for $30 \mathrm{~min}$, and then washed. Colonies were counted and photographed.

Analysis of cell proliferation. Cells (at a density of $2 \times 10^{5} / 100 \mu \mathrm{l}$ ) were seeded into 96-well plates following transduction with siRNA or the negative control lentivirus for $12 \mathrm{~h}$. Then, the Cell Counting kit-8 (CCK-8; Beyotime Institute of Biotechnology, Haimen, China) reagent $(10 \mu \mathrm{l})$ was added to each well at 24 , 48 and $72 \mathrm{~h}$ post-transduction. The plates were then incubated for $4 \mathrm{~h}$ at $37^{\circ} \mathrm{C}$. Absorbance values were measured at a wavelength of $450 \mathrm{~nm}$ in an ELISA reader (Bio-Rad Laboratories, Inc., Hercules, CA, USA), and the proliferation rate of each group was analyzed.

Wound healing assay. Cells were seeded into 6-well plates and cultured till the density reaches $80-90 \%$ confluence. A wound was made using a $1 \mathrm{ml}$ plastic pipette tip then cells were washed twice with PBS. Subsequently, the medium was replaced by DMEM containing 2\% FBS. The size of the wound was 
measured under a microscope (Olympus Corporation, Tokyo, Japan) at 0 and $24 \mathrm{~h}$ after wounding. For each wound, the width of the wound at $0 \mathrm{~h}$ was designated as $100 \%$, and after $24 \mathrm{~h}$ the relative width of the open wound was calculated using ImageJ software (National Institutes of Health, Bethesda, MD, USA) (18).

Transwell invasion assay. Cell invasion assay was carried out using a 24-well Transwell chamber (Corning Incorporated, Corning, NY, USA). Matrigel (BD Biosciences, San Jose, CA, USA) was diluted to 1:8 with cold DMEM without FBS and used to coat the upper compartment chamber. Different groups of cells $\left(2 \times 10^{4}\right)$ were then plated into the upper wells with $100 \mu \mathrm{l}$ serum-free DMEM and the bottom chamber was filled with DMEM containing $10 \% \mathrm{FBS}$. After incubation at $37^{\circ} \mathrm{C}$ for $24 \mathrm{~h}$, noninvasive cells on the top chambers were gently wiped with cotton wool. Invasive cells on the bottom surface were fixed with $4 \%$ paraformaldehyde for $30 \mathrm{~min}$ at $37^{\circ} \mathrm{C}$ and stained with $0.1 \%$ crystal violet for $2 \mathrm{~h}$ at room temperature, then counted under a light microscope. The experiment for each group was performed in triplicate and the results were averaged.

Flow cytometryanalysis of apoptosis. Apoptosis was measured with Annexin V-phycoerythrin (PE) Apoptosis Detection kit (BD Biosciences). The cells $\left(2 \times 10^{5}\right.$ cells/well) were plated in 6 -well plates for $24 \mathrm{~h}$. Then, the cells were washed with cold PBS and resuspended in $100 \mu 11 \mathrm{X}$ binding buffer, followed by the addition of $5 \mu \mathrm{l}$ Annexin V-PE and $5 \mu \mathrm{l}$ 7-aminoactinomycin D (7-AAD). The cells were incubated for $15 \mathrm{~min}$ at room temperature in the dark. Finally, $380 \mu 11 \mathrm{X}$ binding buffer was added to the cells. Cell apoptosis was analyzed using a flow cytometer and CXP analysis software 2.2 (Beckman Coulter, Inc., Brea, CA, USA).

Western blot analysis. Cells were harvested, washed twice with PBS, lysed in ice-cold radioimmunoprecipitation assay buffer (Beyotime Institute of Biotechnology) with a freshly added $0.01 \%$ protease inhibitor cocktail (Sigma-Aldrich; Merck $\mathrm{KGaA}$ ) and incubated on ice for $30 \mathrm{~min}$. Protein concentration was measured by bicinchoninic acid protein assay kit (Beyotime Institute of Biotechnology). Equal amounts of protein $(30 \mu \mathrm{g})$ were subjected to $10 \%$ SDS-PAGE and then were transferred onto the polyvinylidene difluoride membranes (EMD Millipore, Billerica, MA, USA). The membranes were blocked with Western Blocking Buffer (Beyotime Institute of Biotechnology) for $2 \mathrm{~h}$ at room temperature and incubated with primary antibodies at $4^{\circ} \mathrm{C}$ overnight. The membranes were washed with PBS with $0.1 \%$ Tween-20 before incubating them with horseradish peroxidase (HRP)-conjugated anti-rabbit secondary antibodies (1:5,000; cat. no. 7074; Cell Signaling Technology, Inc., Danvers, MA, USA) or HRP-conjugated anti-mouse secondary antibodies $(1: 3,000$; cat. no. XR-9720; ProSci Incorporated, Poway, CA, USA) for $2 \mathrm{~h}$ at room temperature. After washing again, protein levels were analyzed by Pierce ${ }^{\mathrm{TM}}$ Fast Western Blot Kit Enhanced Chemiluminescence Substrate (ECL; cat. no. 3050; Thermo Fisher Scientific, Inc., Waltham, MA, USA) and western blotting detection system (Odyssey CLx; Gene Company, Ltd., Hong Kong, China). The bands were quantified by densitometry using ImageJ 1.46r software (National Institutes of Health, Bethesda, MD, USA). The following antibodies were used in this study: GAPDH (1:1,000; cat. no. sc-69778) and $\beta$-actin (1:1,000; cat. no. sc-58673; Santa Cruz Biotechnology, Inc., Dallas, TX, USA) were used as internal controls. Bcl2 associated X apoptosis regulator (BAX; 1:1,000; cat. no. sc-4239 WB; Santa Cruz Biotechnology, Inc.), apoptosis regulator $\mathrm{Bcl} 2$ (Bcl2; 1:1,000; cat. no. sc-23960; Santa Cruz Biotechnology, Inc.); vascular endothelial growth factor (VEGF; 1:1,000; cat. no. sc-365578) and hypoxia-inducible factor-1 $\alpha$ (HIF-1 $\alpha$; 1:1,000; cat. no. sc-13515); Santa Cruz Biotechnology, Inc.), cleaved caspase3 (cat. no. 9664), caspase3 (cat. no. 9662), Erk1/2 (cat. no. 4695), phospho (p)-Erk1/2 (cat. no. 4370), matrix metalloproteinase 2 (MMP2; cat. no. 40994), E-cadherin (cat. no. 14472) and vimentin (cat. no. 5741) were acquired from Cell Signaling Technology, Inc. and RNF138 (cat. no. DF4025; Affinity Biosciences, Cincinnati, OH, USA) at a dilution of 1:1,500.

Nude mouse model of intracranial glioma. All experimental protocols were approved by the Institutional Review Board of the Department of Laboratory Animal Science of the First Affiliated Hospital of Soochow University (Suzhou, China). All animal manipulations were performed under sterile conditions. BALB/c-A nude female mice at 4 weeks of age were purchased from the Shanghai Experimental Animal Center of the Chinese Academy of Sciences (Shanghai, China) were randomly assigned into two groups $(n=11$ per group). U87 cells ( $3 \times 10^{5}$ cell transduced with lentivirus containing siRNA-RNF138 or negative control sequences) in $4 \mu \mathrm{DMEM} / \mathrm{F} 12$ were injected $3 \mathrm{~mm}$ deep into the frontal lobe, $1.8-2.0 \mathrm{~mm}$ to the right side of the sagittal suture and $1.8-2 \mathrm{~mm}$ anterior to the coronal suture using an astereotactic frame. Mice were observed daily, weighed two times a week until severe neurological deficit and/or $20 \%$ weight-loss and the following day was recorded as the survival date $(19,20)$. For mice found dead, the previous day was recorded as the survival date.

Histology and immunohistochemical staining. Tissues were fixed in $4 \%$ buffered formaldehyde for $24 \mathrm{~h}$ at $4{ }^{\circ} \mathrm{C}$. Paraffin-embedded tissue sections ( $5 \mu \mathrm{m}$ thickness) were placed on positively charged slides and air-dried. Following drying, slides were incubated in a $60^{\circ} \mathrm{C}$ oven for $30 \mathrm{~min}$. Sections were deparaffinized with two xylene washes for $10 \mathrm{~min}$ each at room temperature, then rehydrated using two incubations in absolute alcohol of $5 \mathrm{~min}$ each at room temperature, then incubated in $95 \%$ alcohol for $2 \mathrm{~min}$ and $70 \%$ alcohol for $2 \mathrm{~min}$ at room temperature. Sections were washed briefly in distilled water and stain in Harris hematoxylin solution for $10 \mathrm{~min}$ at room temperature prior to washing in running tap water for $5 \mathrm{~min}$ at room temperature. Differentiation was peformed in $1 \%$ acid alcohol for $30 \mathrm{sec}$ at room temperature then sections were washed in running tap water for $1 \mathrm{~min}$. Bluing was performed in $0.2 \%$ ammonia water for $30 \mathrm{sec}$ at room temperature. Sections were washed in running tap water for 5 min at room temperature and rinsed in 95\% alcohol, 10 dips at room temperature. Counterstaining was performed using eosin-phloxine solution for $30 \mathrm{sec}$ at room temperature; then sections were dehydrated through $95 \%$ alcohol, two changes of 


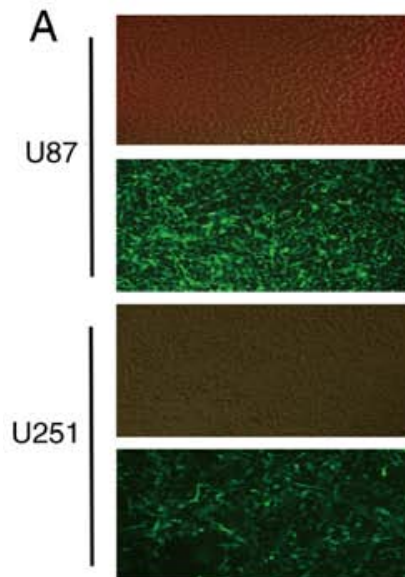

Negative
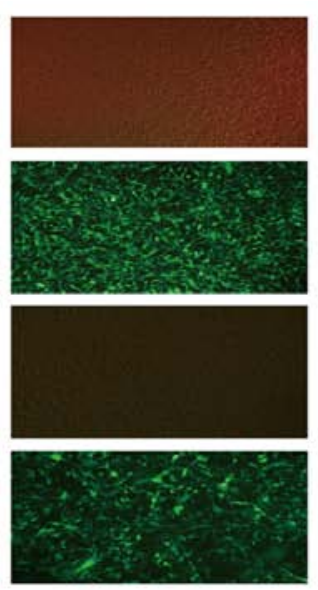

RNF138-siRNA
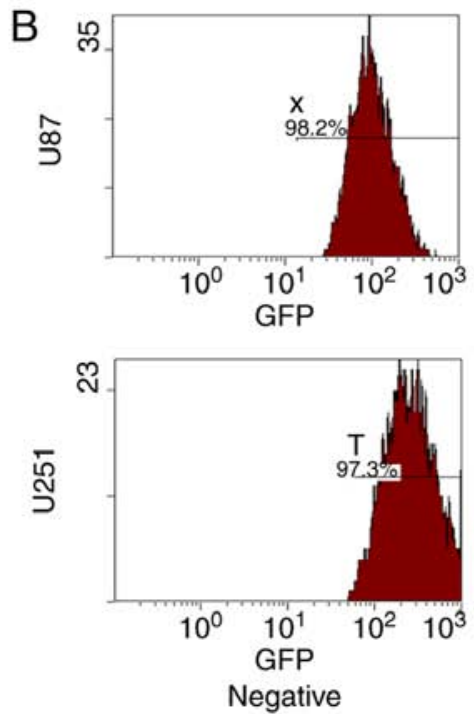
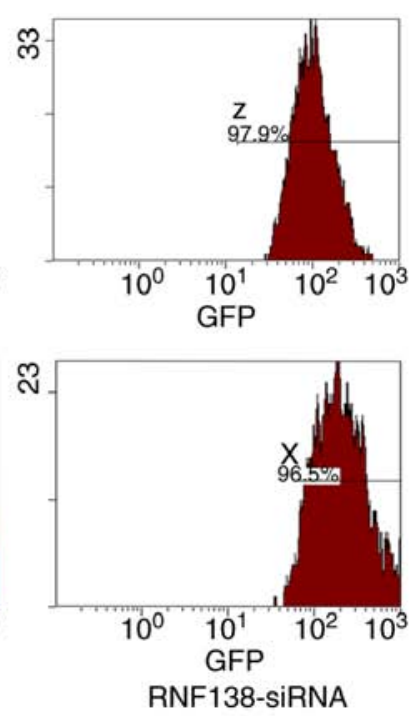

Figure 1. Transduction efficiency of U87 and U251 transduced with RNF138-siRNA and negative control lentivirus. (A) Fluorescence inverted microscope images of U87 and U251 transfected with RNF138-siRNA-lentivirus and negative control lentivirus. (B) Transduction efficiency of U87 and U251 transduced with RNF138-siRNA and the negative control lentivirus was determined by flow cytometry. RNF138, ring finger protein 138; siRNA, small interfering RNA.

absolute alcohol for 5 min each at room temperature. Sections were cleared in two incubations with xylene for 5 min each at room temperature. Digital images were acquired using a light microscope (Olympus BX40; Olympus Corporation).

For immunoreactivity staining, $5 \mu \mathrm{m}$ deparaffinized polysine-coated sections were treated with $3 \%$ hydrogen peroxide for $5 \mathrm{~min}$ at room temperature to remove endogenous oxides. The cells were treated using citrate buffer (BioGenex Laboratories, Fremont, CA, USA) for $5 \mathrm{~min}$ at $100^{\circ} \mathrm{C}$, and permeabilized with $0.3 \%$ Triton $\mathrm{X}-100$. The slides were incubated with primary antibodies, including Ki-67 (1:50; cat. no. sc-56319; Santa Cruz Biotechnology, Inc.) and MMP2 (1:150; cat. no. 40994), E-cadherin (1:100; cat. no. 14472), VEGF (1:100; cat. no. sc-365578) and vimentin (1:100; cat. no. 5741; Cell Signaling Technology, Inc.) at $4^{\circ} \mathrm{C}$ overnight, followed by incubation with a biotin-labeled secondary antibody (1:100 dilution; cat. no. ab64264; Abcam, Cambridge, MA, USA) for $1 \mathrm{~h}$ at room temperature. $5 \%$ diaminobenzidine (Abcam) solution for $10 \mathrm{~min}$ at room temperature was used for brown color development. Immunohistochemical signals were observed under a microscope (Olympus Corporation).

Statistical analysis. All results are expressed as the mean \pm standard deviation from at least three replicates. One-way analysis of variance and Tukey test, or Student's unpaired t-test was used to analyze significance using SPSS 16.0 software (SPSS, Inc., Chicago, IL, USA). The Kaplan-Meier method was used to plot the survival curves followed by a log-rank test. Survival analysis was performed using GraphPad Software version 6.0 (GraphPad Software, Inc., La Jolla, CA, USA). P<0.05 was considered to indicate a statistically significant difference.

\section{Results}

Successful establishment of stable RNF138 expression downregulation in U87 and U251 cell lines. According to our previous research (10), U87 and U251 cell lines exhibited relatively higher RNF138 expression compared with noncancerous brain samples, and hence, these two cell lines were chose for RNF138 silencing experiments. To determine the effect of RNF138, lentiviral siRNA was used to stably and specifically reduce the expression of RNF138 in U87 and U251 cells established from high-grade tumors.

The transfection efficiency of U87 and U251 cells transfected with RNF138-siRNA and the negative control lentivirus was determined by fluorescence inverted microscope and flow cytometry. The phase contrast fluorescence inverted microscopic evaluation revealed $>95 \%$ transfected cells (Fig. 1A) and flow cytometry analysis revealed $>95 \%$ GFP-positive cells (Fig. 1B). RNF138 mRNA and protein expression levels were measured by RT-qPCR and western blotting analyses, respectively. Results revealed that RNF138 protein (Fig. 2A and B) and mRNA expression levels (Fig. 2C) were significantly attenuated compared with the negative control lentiviral groups $(\mathrm{P}<0.01)$.

Stable downregulation of RNF138 expression inhibits malignant glioma cell proliferation, migration and invasion in vitro. The biological function of RNF138 in malignant glioma was analyzed. U87 and U251 cell lines were selected to investigate the effects of RNF138 on cell proliferation, migration and invasion following transduction with RNF138-siRNA and negative control lentiviruses. Colony formation and CCK- 8 assays were performed after transfection of the cells. Colony formation assay (Fig. 3A) demonstrated that U87 and U251 cells infected with RNF138-siRNA decreased the colony formation compared with the negative control lentiviral groups $(\mathrm{P}<0.01$; Fig. 3B). CCK-8 assay revealed that the downregulation of RNF138 led to a significant reduction of cell proliferation in U251 and U87 cells compared with negative control lentiviral groups ( $\mathrm{P}<0.01$; Fig. $3 \mathrm{C}$ and $\mathrm{D})$. These results indicated that silencing of RNF138 suppresses glioma cell proliferation.

To investigate whether the downregulation of RNF138 in U87 and U251 cells affected their migratory and invasive 


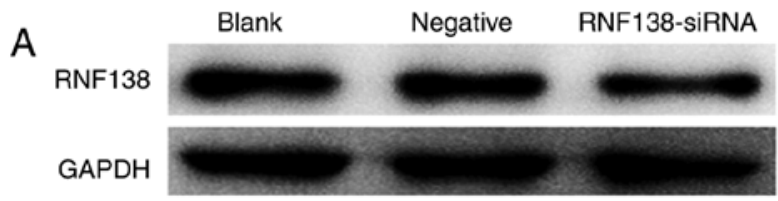

U87

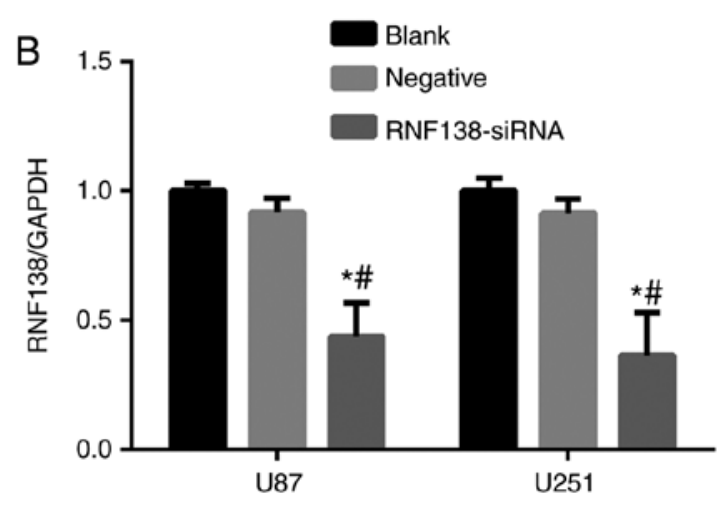

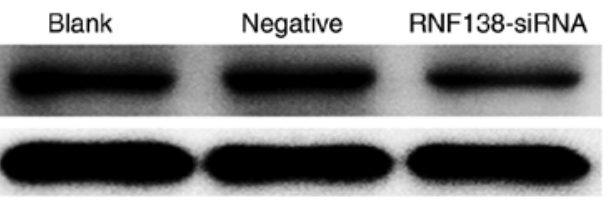

U251

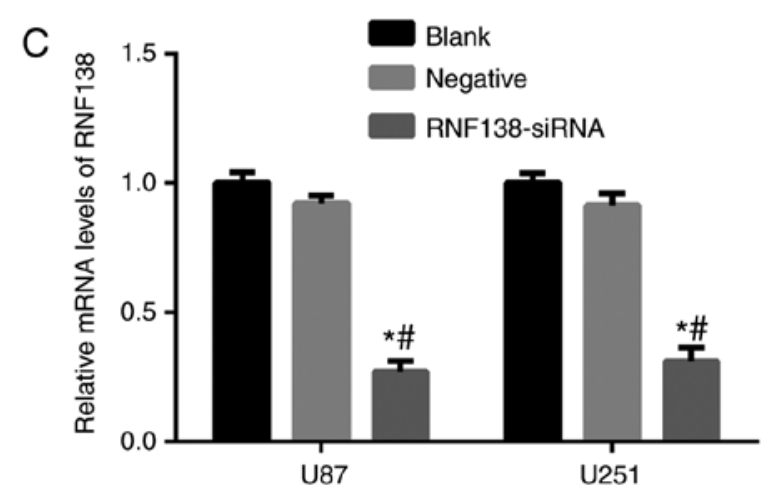

Figure 2. Stable downregulation RNF138 expression in the human glioma cell lines U87 and U251. (A) Western blot assay demonstrated RNF138 protein expression levels in cells transduced with RNF138-siRNA lentivirus and the negative control lentivirus. GAPDH served as the loading control. (B) Relative densitometry analysis of RNF138 and GAPDH expression by western blot in U87 and U251 cells. (C) Reverse transcription-quantitative polymerase chain reaction analysis of the mRNA expression levels of RNF138 with GAPDH as the reference control. Data are presented as the mean \pm standard deviation for three independent experiments. ${ }^{*} \mathrm{P}<0.01$ vs. blank; ${ }^{*} \mathrm{P}<0.01$ vs. negative group. RNF138, ring finger protein 138 ; siRNA, small interfering RNA.

U87

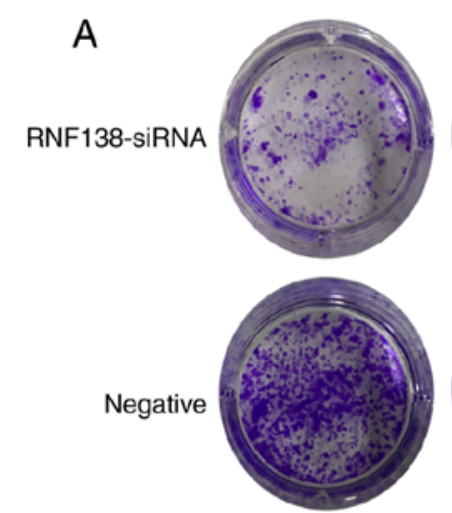

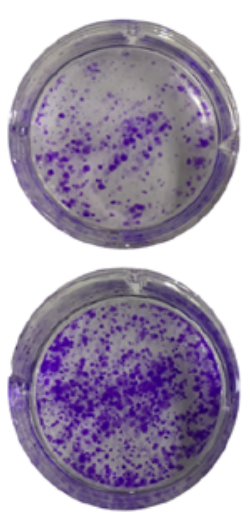

U251

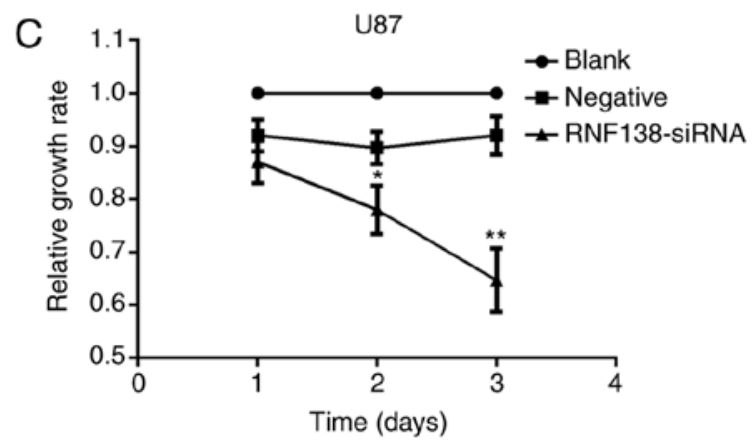

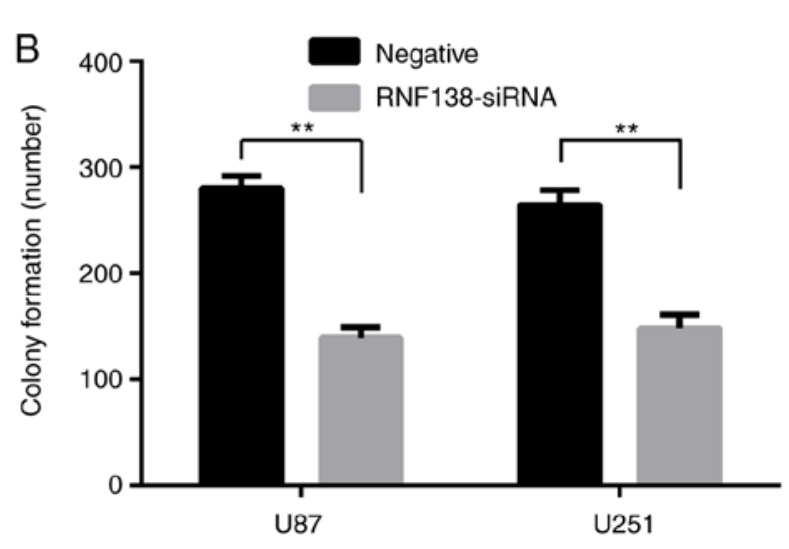

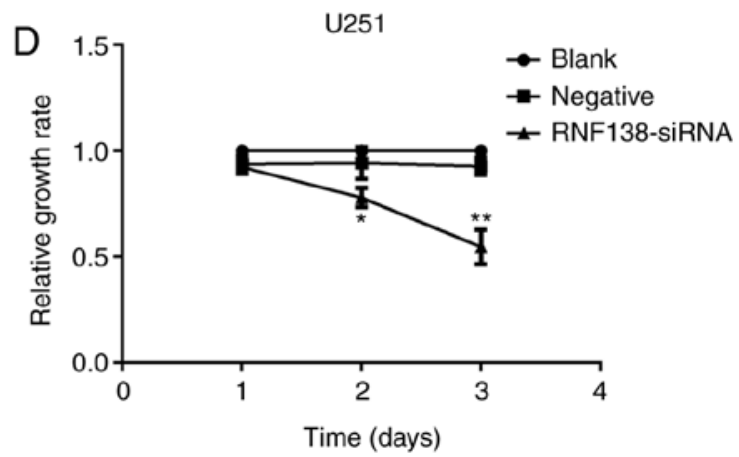

Figure 3. Stable downregulation of RNF138 suppresses cell proliferation in vitro. (A) Colony formation assay was performed to determine the proliferation of U87 and U251 cells transfected with RNF138-siRNA lentivirus and the negative control lentivirus. (B) Colony number of U87 and U251 cells per well in 6-well plates cultured for 14 days. CCK-8 assay revealed decreased proliferation in (C) U87 and (D) U251 following downregulation of RNF138. Data are presented as the mean \pm standard deviation for three independent experiments. ${ }^{* *} \mathrm{P}<0.01$ vs. negative group. RNF138, ring finger protein 138; siRNA, small interfering RNA.

abilities in vitro, wound healing and Transwell assays were performed. Results of wound healing assay (Fig. 4A) demonstrated that downregulation of RNF138 resulted in a decrease in the migration compared with negative control 
A
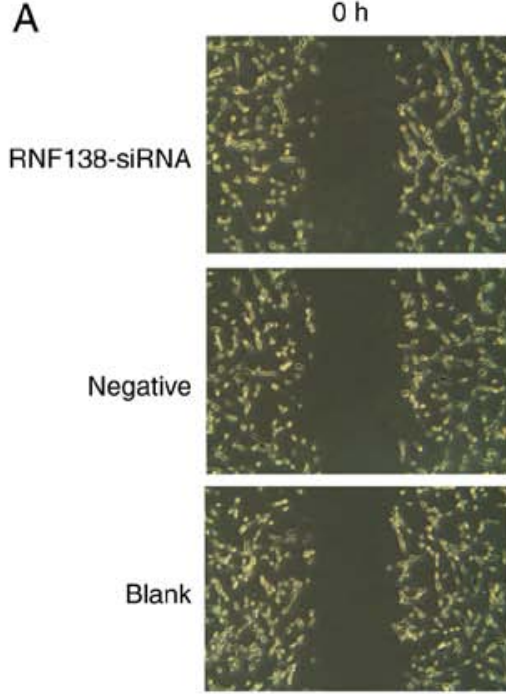

$24 \mathrm{~h}$
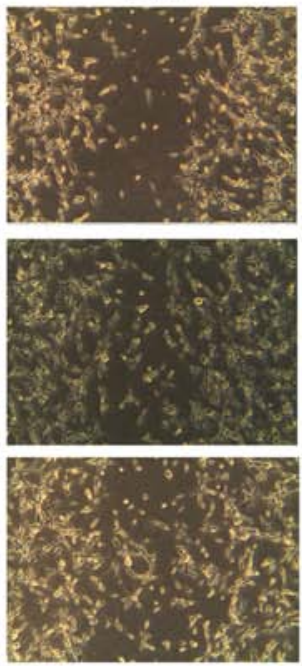

U87
$\mathrm{Oh}$
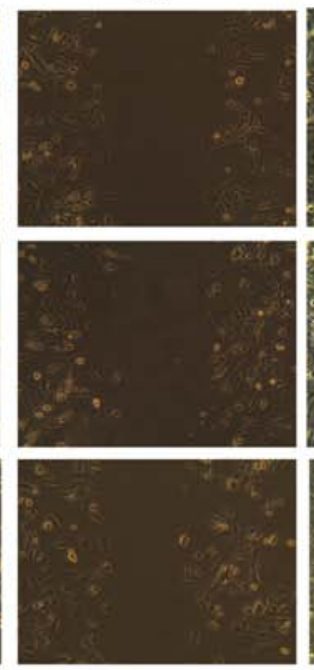

U251
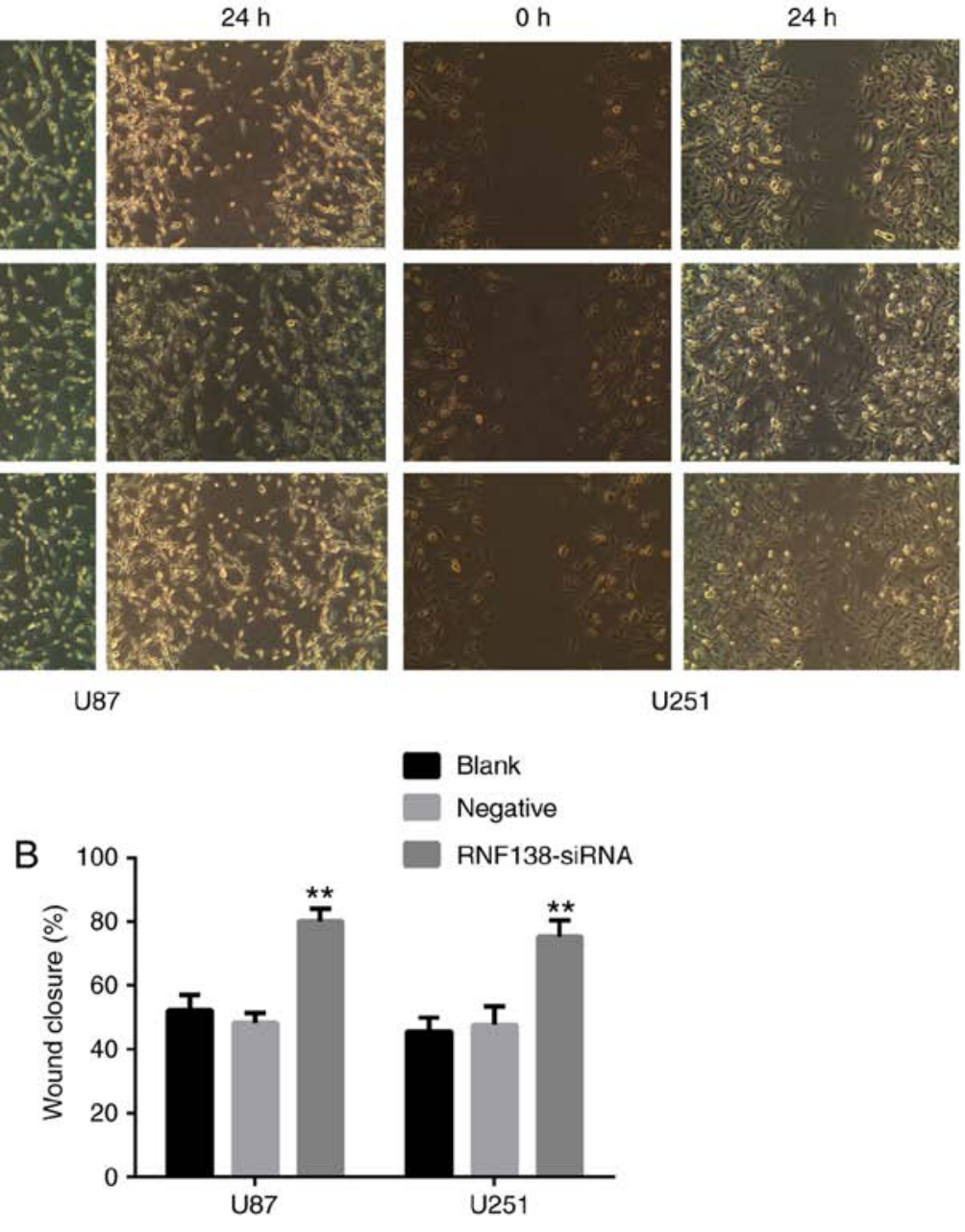

C
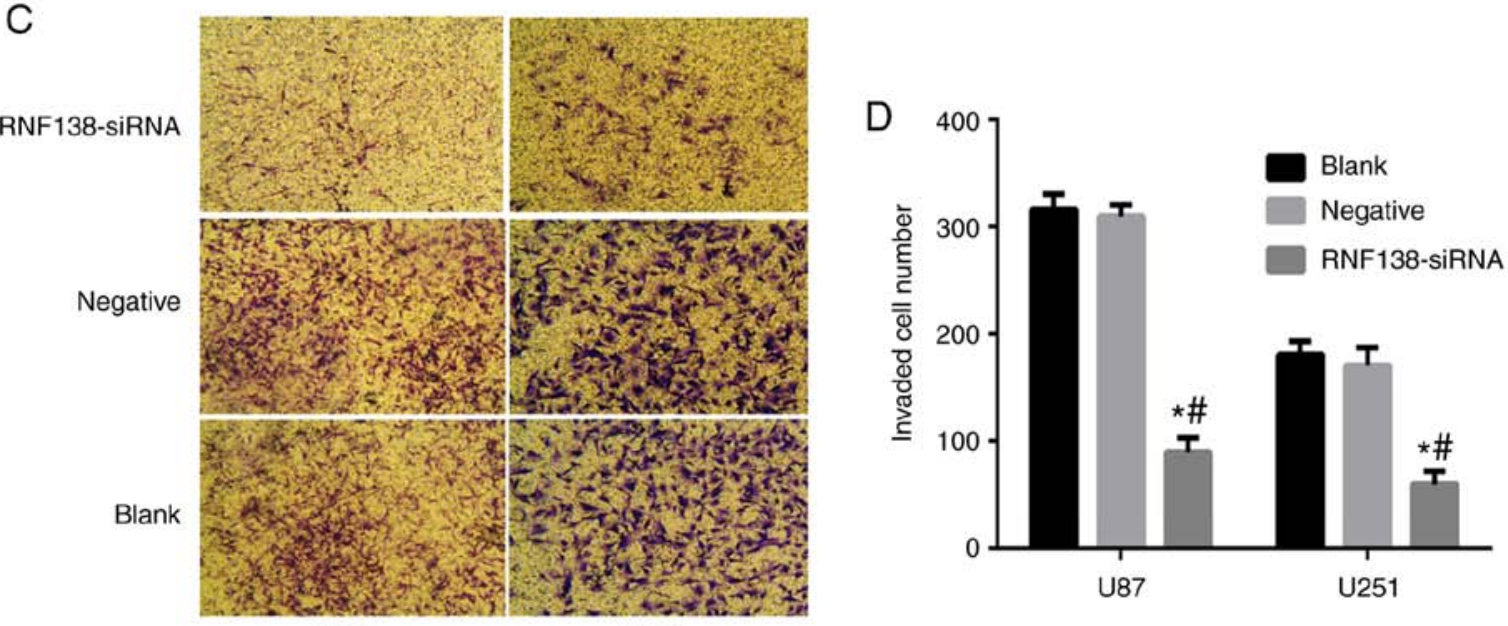

U87

U251

Figure 4. Suppression of RNF138 reduces the invasion and migration ability of U87 and U251 cell lines in vitro. (A) Scratch wound assay results of U87 and U251 transduced with RNF138-siRNA lentivirus, negative control lentivirus and blank groups (original magnification, x40). (B) Quantification U87 and U251 cell migration transduced with RNF138-siRNA, negative control and blank groups at $24 \mathrm{~h} .{ }^{* *} \mathrm{P}<0.01$ vs. negative and blank group. (C) Transwell assay exhibited invasion of U87 and U251 cells transduced with RNF138-siRNA lentivirus, negative control lentivirus. (D) Quantification of the invasion of U87 and U251 cells transduced with RNF138-siRNA, negative control and blank groups (original magnification, x100). Data are presented as the mean \pm standard deviation for three independent experiments. ${ }^{*} \mathrm{P}<0.01$ vs. negative and ${ }^{\#} \mathrm{P}<0.01$ blank group. RNF138, ring finger protein 138; siRNA, small interfering RNA.

lentivirus groups $(\mathrm{P}<0.01$; Fig. 4B), suggesting the reduced migration-promoting abilities of RNF138 in the knockdown samples. Additionally, the experimental results of the Transwell assay demonstrated that the number of cells invading through the chamber was decreased significantly by RNF138-siRNA compared to negative control lentiviral groups $(\mathrm{P}<0.01$; Fig. 4C and D), indicating that RNF138 has an important role in glioma cell invasion. To further elucidate the detailed mechanism, the protein level changes of HIF-1 $\alpha$, VEGF and MMP2 were determined by western blotting (Fig. 5A). Western blot 


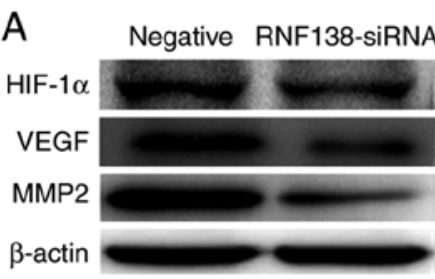

U87
Negative RNF138-siRNA

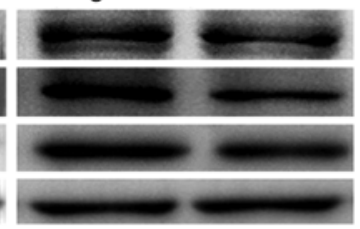

U251
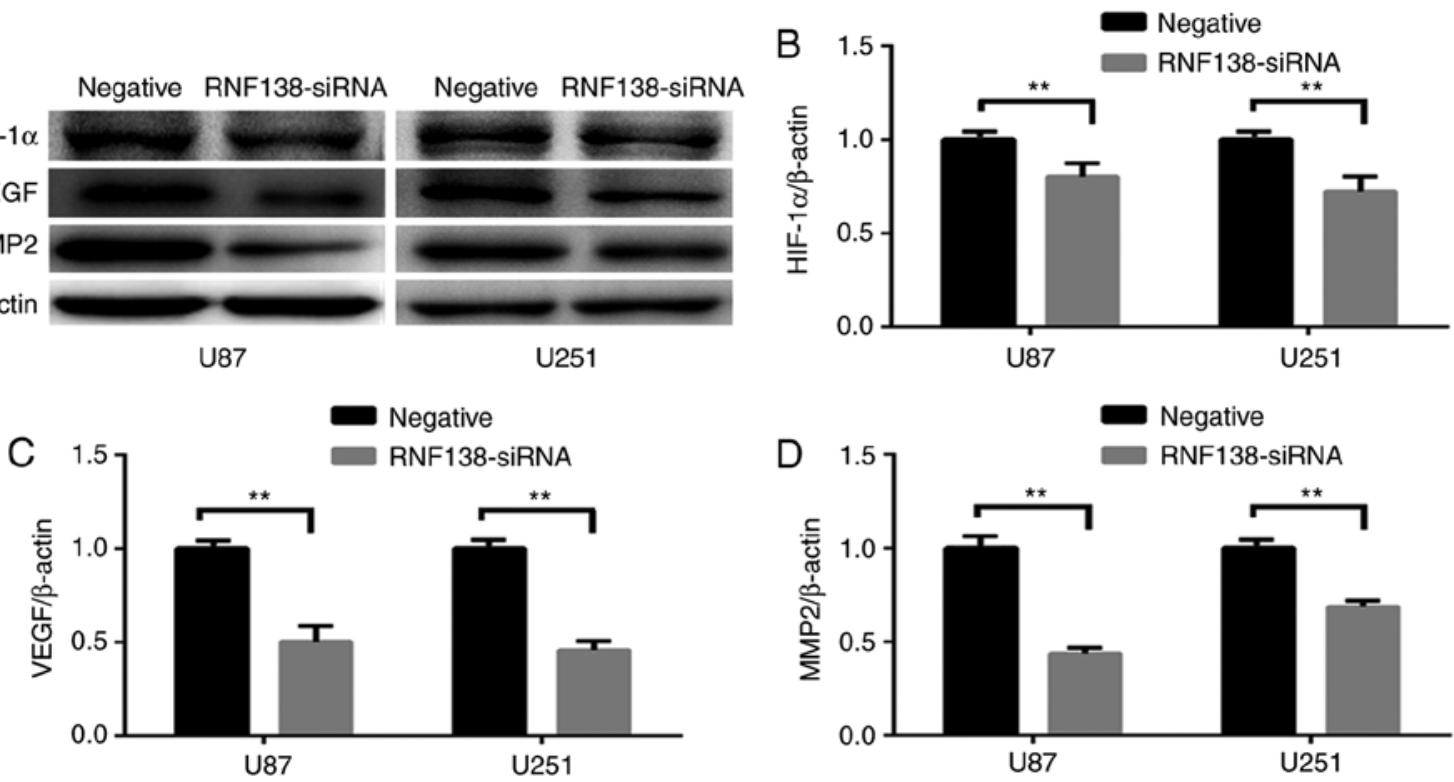

Figure 5. RNF138 regulates the protein levels of HIF-1 $\alpha$, VEGF and MMP2 in glioma cell lines. (A) Western blotting analysis of HIF-1 $\alpha$, VEGF and MMP2 expression in U87 and U251 cells, $\beta$-actin was used as a loading control. Densitometry analysis of (B) HIF-1 $\alpha$, (C) VEGF and (D) MMP2 expression in U87 and $\mathrm{U} 251$ using Image $\mathrm{J}$ analysis. Data are presented as the mean \pm standard deviation for three independent experiments. ${ }^{* *} \mathrm{P}<0.01$. RNF138, ring finger protein 138; siRNA, small interfering RNA; HIF-1 $\alpha$, hypoxia-inducible factor-1 $\alpha$; VEGF, vascular endothelial growth factor; MMP2, matrix metalloproteinase 2.

A
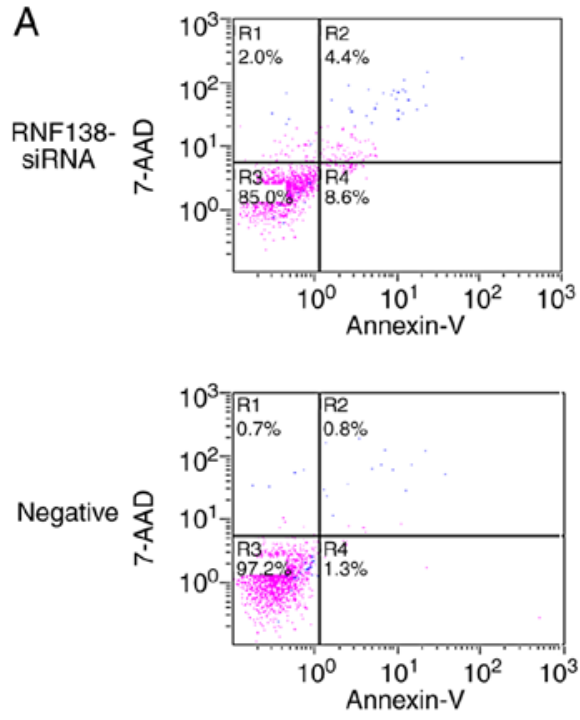

U87
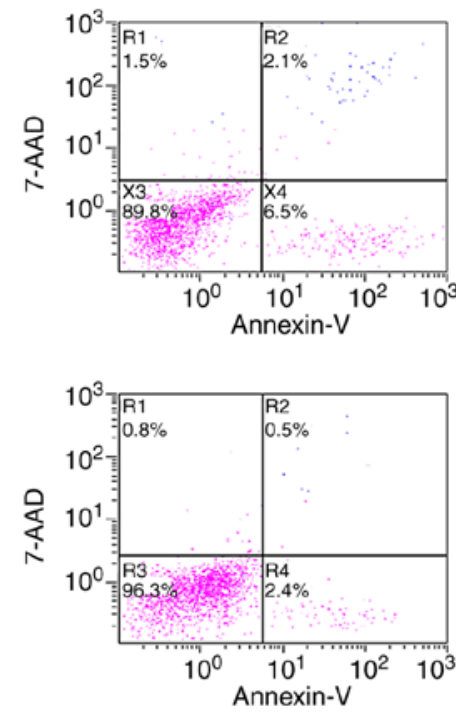

U251

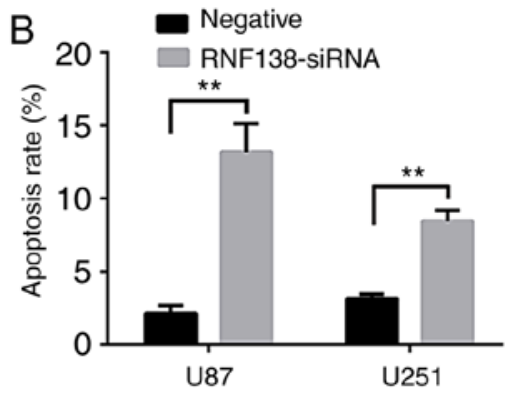

Figure 6. Apoptotic rates of U87 and U251 transduced with RNF138-siRNA and negative control lentivirus. (A) Transfection with RNF138-siRNA in U87 and U251 cells significantly increased cell apoptosis compared with negative control groups by flow cytometry detection. (B) Quantification of flow cytometry data. Quadrant R2 and X4 were apoptotic cells. Data are presented as the mean \pm standard deviation for three independent experiments. ${ }^{* *} \mathrm{P}<0.01$. RNF138, ring finger protein 138; siRNA, small interfering RNA; 7-AAD, 7-aminoactinomycin D.

analysis revealed significant decrease of HIF-1 $\alpha$, VEGF and MMP2 protein levels by downregulating RNF138 compared with the negative control $(\mathrm{P}<0.01$; Fig. $5 \mathrm{~B}-\mathrm{D})$. These data demonstrated that knockdown of RNF138 inhibited glioma cell migration and invasion, potentially via downregulation of HIF-1 $\alpha$, VEGF and MMP2 expression levels. The data implied that RNF138 has a critical role in glioma cell proliferation, migration and invasion.

Knockdown of RNF138 increased apoptosis of glioma cells through caspase pathway. Annexin V-PE apoptosis detection and flow cytometry analysis were used to examine whether knockdown of RNF138 inhibited glioma cell proliferation by inducing cell apoptosis. Annexin V-PE and 7-AAD to evaluate the apoptosis of GFP-positive U251 and U87 cell lines. The results revealed that knockdown of RNF138 may induce cell apoptosis (Fig. 6A). The proportion of apoptotic cells following RNF138 siRNA was significantly increased in U87 and U251 cells compared with negative control lentiviral groups $(\mathrm{P}<0.01$; Fig. 6B). Subsequently, the protein levels of apoptotic-associated factors (BAX, Bcl2, cleaved caspase 3 and caspase 3 ) were determined using western blotting (Fig. 7A). Notably, the 
A

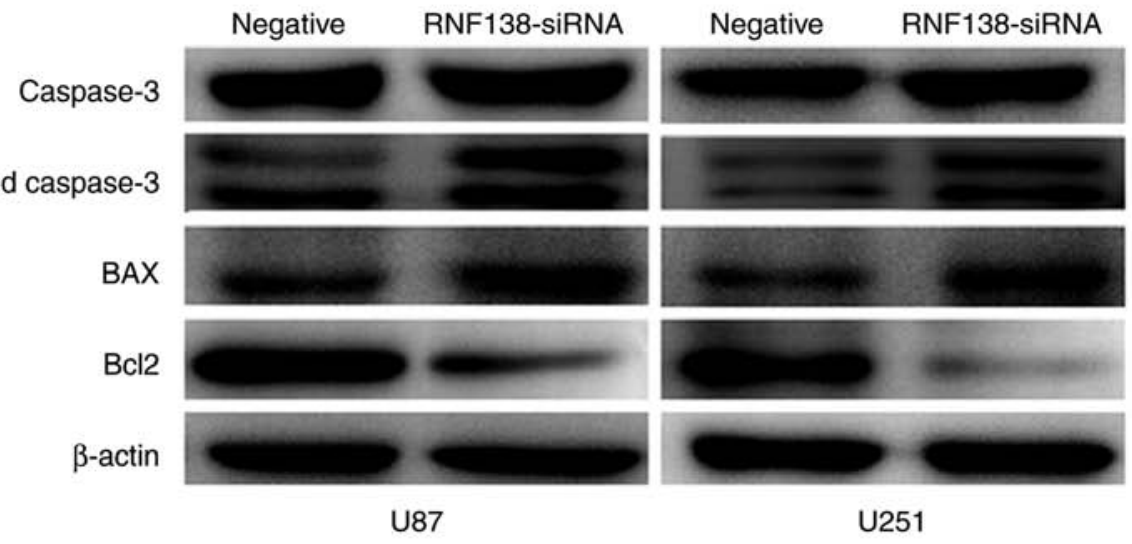

B
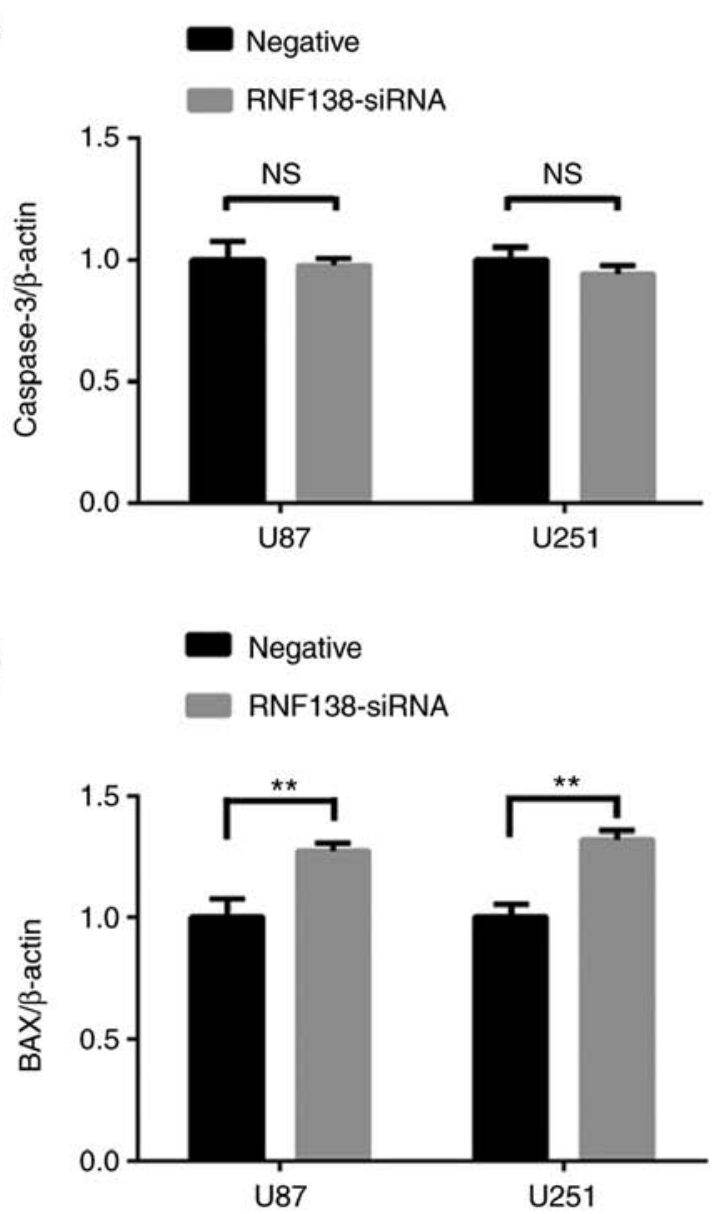

C
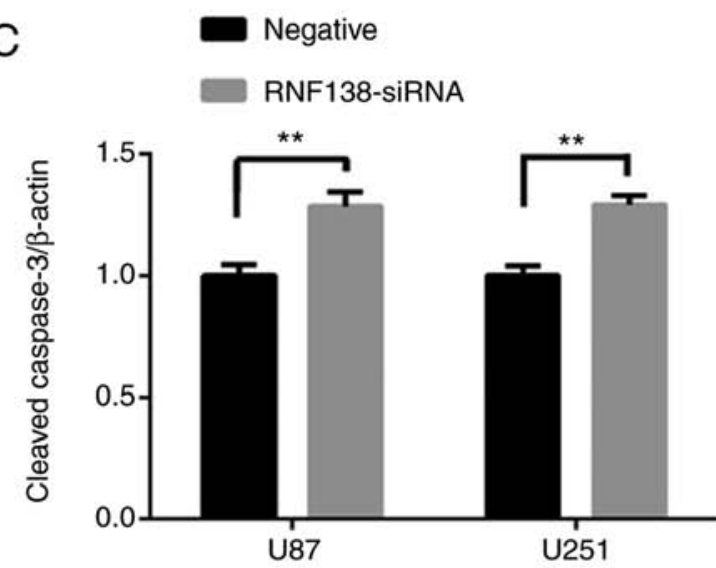

$E$

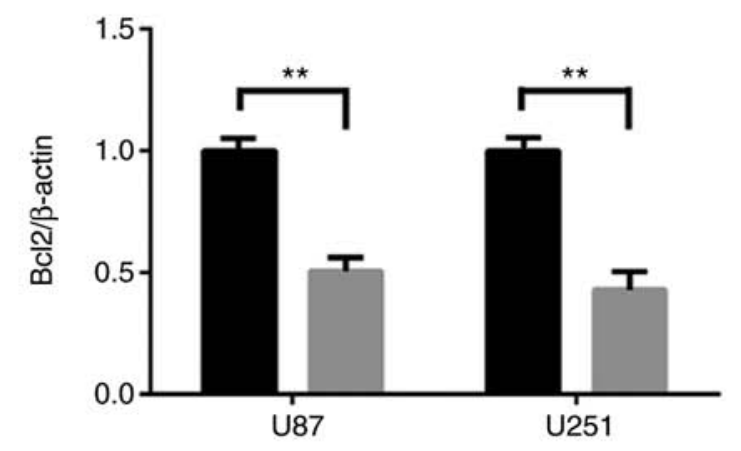

Figure 7. Protein levels of apoptotic-associated factors in U87 and U251 cells transduced with RNF138-siRNA and negative control lentivirus. (A) Expression of caspase3, cleaved caspase3, BAX and Bcl2 were detected by western blot analysis. $\beta$-actin served as the loading control. Densitometry analysis of (B) caspase3, (C) cleaved caspase3, (D) BAX and (E) Bcl2, relative to $\beta$-actin expression in U87 and U251 cells with ImageJ analysis. Data are presented as the mean \pm standard deviation for three independent experiments. ${ }^{* *} \mathrm{P}<0.01$. RNF138, ring finger protein 138; siRNA, small interfering RNA; BAX, Bcl2 associated $\mathrm{X}$ apoptosis regulator; Bcl2, Bcl2 apoptosis regulator; NS, not significant.

protein of caspase 3 was unchanged in U87 and U251 cells with RNF138 knockdown compared with the negative control lentivirus group $(\mathrm{P}<0.01$; Fig. 7B). Additionally, the protein expression of BAX and cleaved caspase3 (Fig. 7C and D) were upregulated, while Bcl2 (Fig. 7E) was downregulated in the RNF138-siRNA group compared with the negative lentivirus group. Taken together, these data suggested that downregulation of RNF138 inhibited glioma cell proliferation, increased apoptosis of glioma cells through caspase signaling pathway.
Downregulation of RNF138 inhibited EMT in U87 and U251 cells and suppressed the Erk signaling pathway. EMT is a reversible biological process that occurs in cells during normal development and aberrantly activated in various cancer types (21). Previous studies have reported that EMT is closely associated with malignant tumor cell invasion capacity. To further explore whether downregulation of RNF138 expression level could influence EMT in glioma cell lines, the EMT markers E-cadherin and vimentin were measured using western 
A

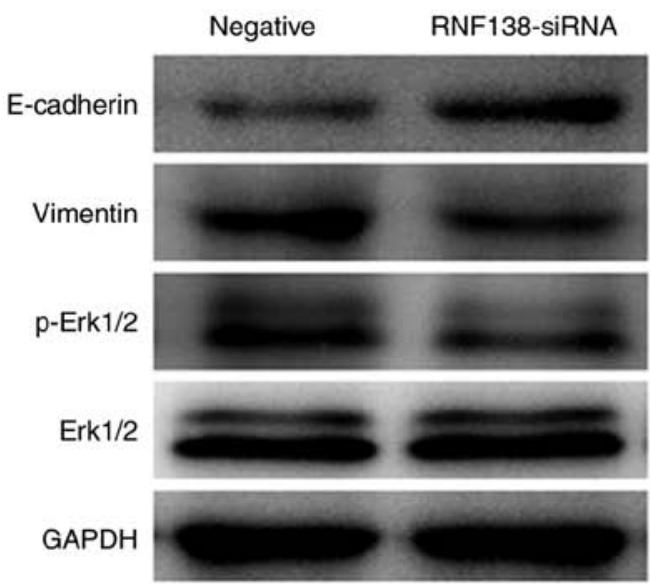

U87
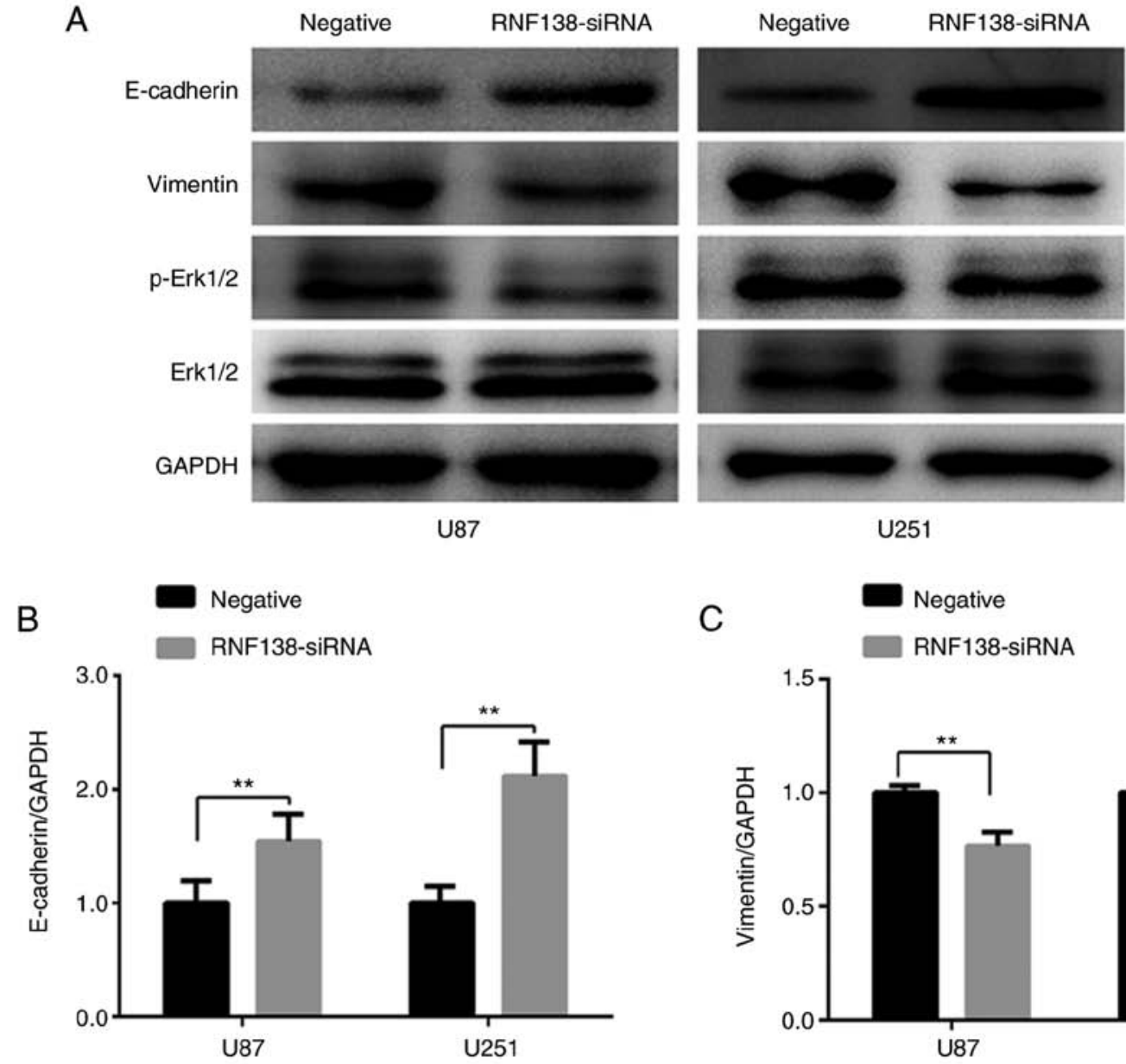

C

Negative
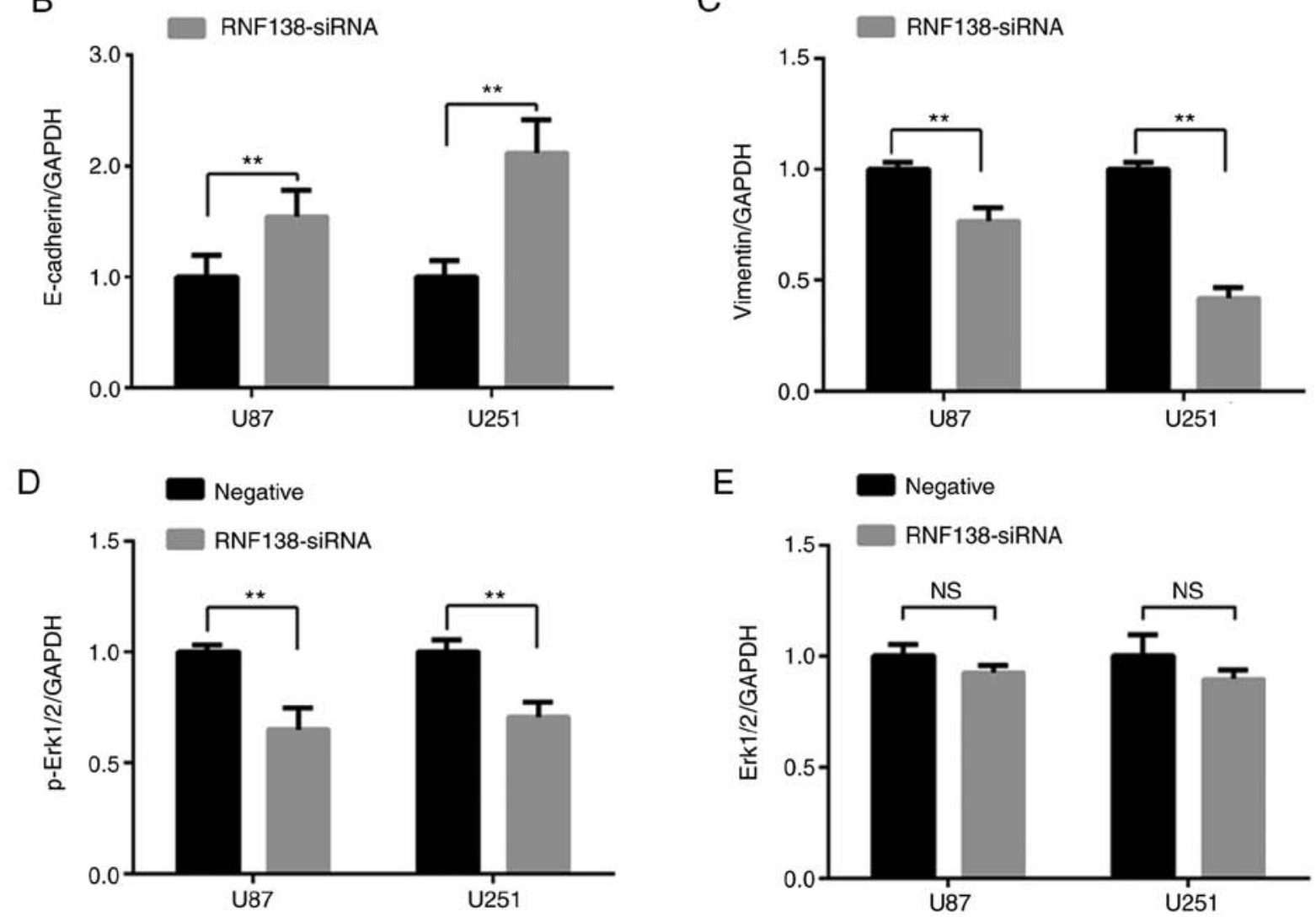

Figure 8. Downregulation of RNF138 inhibits epithelial-mesenchymal transition of U87 and U251 cells by suppressing the Erk signaling pathway. (A) Expression of E-cadherin, vimentin, p-Erk1/2, Erk1/2 and GAPDH in different groups were detected by western blot analysis. Relative gray values of (B) E-cadherin, (C) vimentin, (D) p-Erk1/2 and (E) Erk1/2 relative to GAPDH expression levels in U87 and U251 cells were detected using ImageJ analysis. Data are presented as the mean \pm standard deviation for three independent experiments. ${ }^{* *} \mathrm{P}<0.01$. p-, phospho-; Erk, extracellular signal-regulated kinase; RNF138, ring finger protein 138; siRNA, small interfering RNA; NS, not significant.

blot analysis (Fig. 8A). Compared with the negative control lentiviral cells, the expression level of E-cadherin was significantly increased $(\mathrm{P}<0.01$; Fig. $8 \mathrm{~B})$, while the vimentin levels were decreased in RNF138-siRNA cells ( $\mathrm{P}<0.01$; Fig. 8C).

There are several cell signaling pathways implicated in the process of EMT. Erk signaling pathways has been reported to have a role in modulating cell invasion and progression of EMT $(22,23)$. Western blot analysis was performed to further investigate whether inhibition of RNF138 expression could influence EMT via the Erk signaling pathway. These results revealed that downregulation of RNF138 significantly inhibited the activation of Erk1/2 (P<0.01; Fig. 8D), however, total Erk1/2 levels were unchanged ( $\mathrm{P}>0.01$; Fig. $8 \mathrm{E})$. These data indicate that the downregulation of RNF138 may reverse the EMT process via the Erk signaling pathway in glioblastoma.

Knockdown of RNF138 suppresses tumor growth in an orthotopic nude mice model. As described above, 

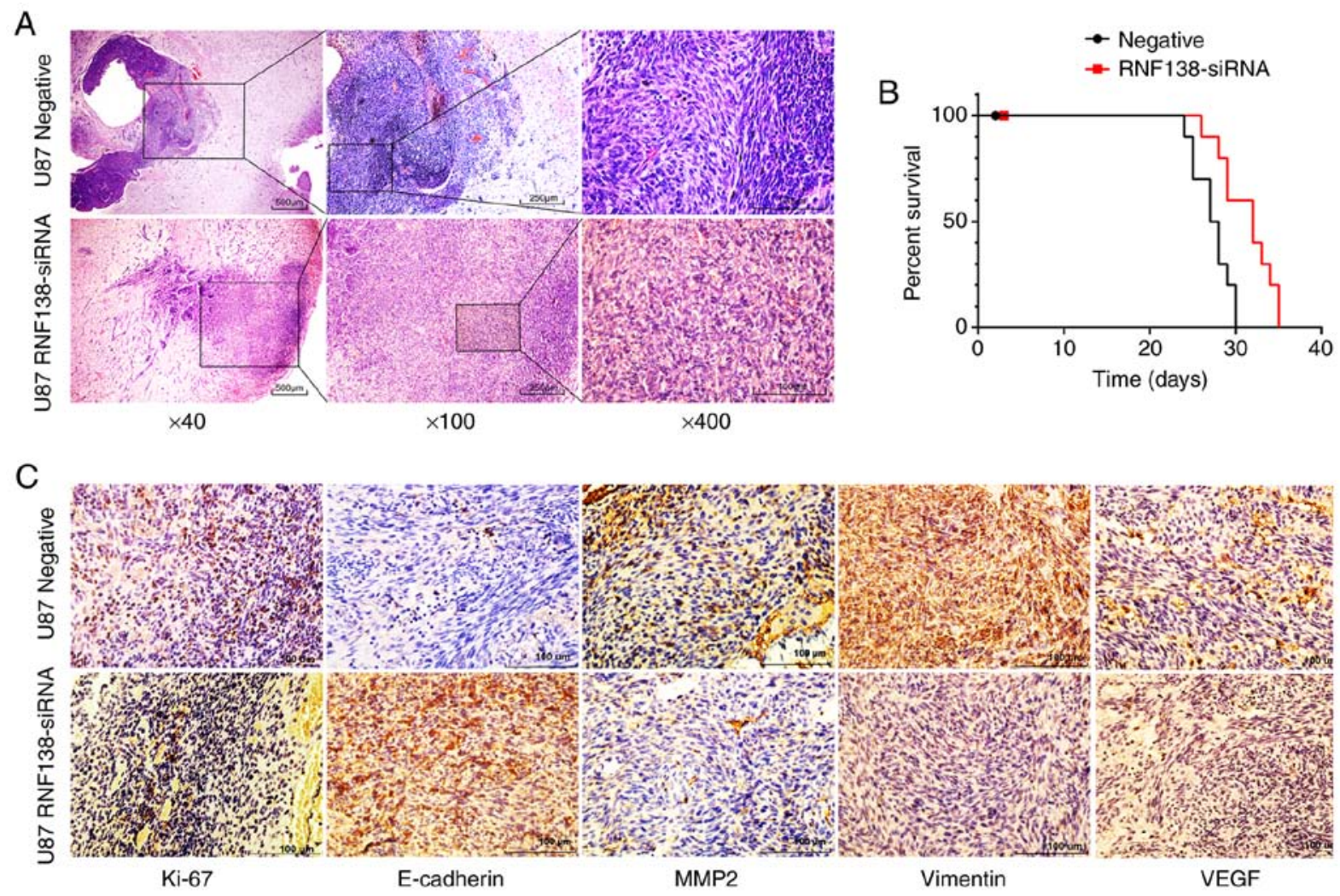

Figure 9. Suppression of RNF138 inhibited tumor proliferation and invasion in vivo. (A) Hematoxylin-eosin staining of the intracranial tumors of the mice in both the groups. (B) The Kaplan-Meier method was used to plot the survival curves followed by a log-rank test. Longer survival in mice of U87-RNF138-siRNA compared to U87-negative lentivirus ( $\mathrm{P}<0.01)$. (C) Immunohistochemistry staining of Ki-67, E-cadherin, MMP2, Vimentin and VEGF of the mice intracranial tumors in both the groups (x400). RNF138, ring finger protein 138; siRNA, small interfering RNA; MMP2, matrix metalloproteinase 2; VEGF, vascular endothelial growth factor.

downregulation of RNF138 suppressed the tumorigenicity of glioma cells in vitro and further analysis is required in vivo. Tumorigenicity was determined in an orthotopic nude mouse model to confirm the function of RNF138 knockdown in vivo. U87 cells with stable expression of RNF138-siRNA or negative control lentivirus were intracranially injected into nude mice. Eleven mice were collected for RNF138-siRNA cells treated group (experiment group), and another eleven mice were treated with Sci-siRNA as control group. Hematoxylin and eosin (H\&E) staining of the tumors resulting from injection with U87 cells revealed decreased cell motion in the RNF138-siRNA group compared with the scramble controls (Fig. 9A), Kaplan-Meier analysis showed survival was prolonged in the RNF138-siRNA group compared with the negative control group $(\mathrm{P}<0.01$; Fig. 9B). Immunohistochemistry revealed that the expression of Ki-67, vimentin, VEGF and MMP2 were lower in the RNF138-siRNA group compared with the negative group, while E-cadherin expression was notably higher than the negative control group (Fig. 9C). These results were consistent with the in vitro results, indicating that knockdown of RNF138 suppressed tumorigenesis of malignant glioma in vivo.

\section{Discussion}

Ubiquitylation is a dynamic and reversible post-translational modification that regulates a wide range of biological processes, including cell cycle progression, transcription, apoptosis and inflammation (24). RNF138 is characterized as an E3 ubiquitin ligase that contains a RING, zinc finger and UIM domains. RNF138 was originally reported to act as a negative regulator of Wnt signaling through Nemo-like kinase (25). Although the upregulation of RNF138 in human glioma tissues has been previously identified (10), the biological functions of RNF138 in glioma cell lines remain largely unknown.

Therefore, CCK- 8 proliferation assay, colony formation assay and flow cytometry were used to explore the effects of RNF138 on migration, proliferation and apoptosis of U87 and U251 cells in vitro. The current study demonstrated decreased migration and invasion, and increased the apoptosis of U87 and U251 glioma cells with RNF138 knockdown. However, the exact molecular mechanisms on how tumor cell proliferation, migration, apoptosis and invasive potential are affected remained unclear.

Apoptosis is a well-orchestrated cellular mechanism of programmed cell death that is mediated through a caspase cascade $(26,27)$. Therefore, the protein levels of apoptosis-associated factors were determined in RNF138-siRNA-infected glioblastoma cells. The levels of both cleaved caspase 3 and BAX were upregulated in U87 and U251 cells with RNF138 silencing. Conversely, the expression levels of Bcl 2 were downregulated by RNF138 knockdown. The current study demonstrated the critical role of regulatory role of RNF138 in apoptosis via the caspase3 pathway in U87 and U251 cells. Apoptotic assay further confirmed the apoptosis inducing function of downregulated RNF138. These findings are supported by the fact that RNF138 silencing induced an increase in the abundance of cleaved caspase 3 protein. 
Hou et al (28) suggested that cancer cells obtain invasion ability via EMT, whereby epithelial cells lose their cell-cell adhesion and attain mesenchymal characteristics. This process has a critical role in the development and progression, invasion and migration of diverse human tumors (28-31). Therefore, to elucidate the precise mechanisms involved in cell migration and invasion, the effects of RNF138 on EMT-associated proteins were examined. The suppression of RNF138 expression resulted in elevated expression of E-cadherin and reduced expression of vimentin, which acts as a crucial step for cancer cell migration and invasion in various cancer types (32-34). These findings indicate that the knockdown of RNF138 potentially reduced EMT in the glioma cell lines.

Erk signaling is associated with the process of EMT, and an essential component of the mitogen-activated protein kinase signal cascades. Erk is associated with the regulation of glioma proliferation, differentiation, migration and apoptosis (35-38). The effect of RNF138 on Erk signaling pathway was also investigated. The level of p-Erk1/2 was notably decreased in RNF138-siRNA glioma cells compared with negative control glioma cells, and cell migration was suppressed following RNF138 knockdown. Thus, the data confirmed that lower expression of RNF138 in glioma cells reversed the EMT process, potentially via the Erk pathway.

In addition, RNF138 knockdown notably decreased MMP2, HIF-1 $\alpha$ and VEGF protein expression levels. MMP2, HIF-1 $\alpha$ and VEGF have been reported to participate in EMT progression in different types of cancer, which was regulated via Erk signaling (39-41). HIF-1 $\alpha$ is stabilized by hypoxia-induced reactive oxygen species, which results in the enhanced expression of several of hypoxia-associated genes, including the VEGF, which is an angiogenic activator (42). Furthermore, immunohistochemistry staining revealed that vimentin, VEGF and MMP2-positive cells were reduced, while E-cadherin was higher in tumors produced from RNF138 knockdown cells than the negative control group. Taken together, these results suggest that suppression of RNF138 reduced the invasion and migration of glioma cells, and regulated the protein levels of HIF-1 $\alpha$, VEGF and MMP2 potentially by reversing EMT via Erk signaling.

\section{Acknowledgements}

The authors thank Shanghai GenePharm Co., Ltd. (Shanghai, China) for providing the interference sequence and technical assistance, the central lab for providing technical instruction and assistance and the Cell Bank Type Culture Collection of the Chinese Academy of Sciences (Shanghai, China) for offering glioma cell lines.

\section{Funding}

This study was partially supported by the National Science Foundation of China (grant no. 81572475) and the Anti-Cancer Association Foundation of China (grant no. CSNO-2016-MSD04).

\section{Availability of data and materials}

The datasets used during the present study are available from the corresponding author upon reasonable request.

\section{Authors' contributions}

HW and XL conducted the majority of experiments, analyzed the results and wrote the majority of the paper. YZ and MF designed the study, coordinated the study and wrote the paper. LY, GZ and ZDe conducted the experiments on cell cultures and lentivirus siRNA gene transfection. SC offered technical instruction and assistance. ZDu performed analysis and interpretation of data. All the authors read and approved the final version of the manuscript.

\section{Ethics approval and consent to participate}

All experimental protocols were approved by the Institutional Review Board of the Department of Laboratory Animal Science of the First Affiliated Hospital of Soochow University (Suzhou, China).

\section{Patient consent for publication}

Not applicable.

\section{Competing interests}

The authors declare that they have no competing interests.

\section{References}

1. Malzkorn B and Reifenberger G: Practical implications of integrated glioma classification according to the World Health Organization classification of tumors of the central nervous system 2016. Curr Opin Oncol 28: 494-501, 2016.

2. Winter SF, Loebel F and Dietrich J: Role of ketogenic metabolic therapy in malignant glioma: A systematic review. Crit Rev Oncol Hematol 112: 41-58, 2017.

3. Ostrom QT, Gittleman H, Liao P, Rouse C, Chen Y, Dowling J, Wolinsky Y, Kruchko C and Barnholtz-Sloan J: CBTRUS statistical report: Primary brain and central nervous system tumors diagnosed in the United States in 2007-2011. Neuro Oncol 16 (Suppl 4): iv1-iv63, 2014.

4. Tanaka S, Louis DN, Curry WT, Batchelor TT and Dietrich J: Diagnostic and therapeutic avenues for glioblastoma: No longer a dead end? Nat Rev Clin Oncol 10: 14-26, 2013.

5. Stupp R, Hegi ME, Mason WP, van den Bent MJ, Taphoorn MJ, Janzer RC, Ludwin SK, Allgeier A, Fisher B, Belanger K, et al: Effects of radiotherapy with concomitant and adjuvant temozolomide versus radiotherapy alone on survival in glioblastoma in a randomised phase III study: 5-year analysis of the EORTC-NCIC trial. Lancet Oncol 10: 459-466, 2009.

6. Carlsson SK, Brothers SP and Wahlestedt C: Emerging treatment strategies for glioblastoma multiforme. EMBO Mol Med 6: 1359-1370, 2014

7. Liang J, Wang WF, Xie S, Zhang XL, Qi WF, Zhou XP, Hu JX, Shi Q and Yu RT: Expression of $\beta$-transducin repeat-containing E3 ubiquitin protein ligase in human glioma and its correlation with prognosis. Oncol Lett 9: 2651-2656, 2015.

8. Liu Y, Wang F, Liu Y, Yao Y, Lv X, Dong B, Li J, Ren S, Yao Y and Xu Y: RNF135, RING finger protein, promotes the proliferation of human glioblastoma cells in vivo and in vitro via the ERK pathway. Sci Rep 6: 20642, 2016.

9. Xu L, Lu Y, Han D, Yao R, Wang H, Zhong S, Luo Y, Han R, $\mathrm{Li} \mathrm{K}, \mathrm{Fu} \mathrm{J}$, et al: Rnf138 deficiency promotes apoptosis of spermatogonia in juvenile male mice. Cell Death Dis 8: e2795, 2017.

10. Zhou YX, Chen SS, Wu TF, Ding DD, Chen XH, Chen JM, Su ZP, Li B, Chen GL, Xie XS, et al: A novel gene RNF138 expressed in human gliomas and its function in the glioma cell line U251. Anal Cell Pathol (Amst) 35: 167-178, 2012.

11. Kalluri R and Weinberg RA: The basics of epithelial-mesenchymal transition. J Clin Invest 119: 1420-1428, 2009.

12. Kang Y and Massagué J: Epithelial-mesenchymal transitions: Twist in development and metastasis. Cell 118: 277-279, 2004. 
13. Thiery JP: Epithelial-mesenchymal transitions in tumour progression. Nat Rev Cancer 2: 442-454, 2002.

14. Thiery JP, Acloque H, Huang RY and Nieto MA: Epithelial-mesenchymal transitions in development and disease. Cell 139: 871-890, 2009.

15. Han MZ, Huang B, Chen AJ, Zhang X, Xu R, Wang J and Li XG: High expression of RAB43 predicts poor prognosis and is associated with epithelial-mesenchymal transition in gliomas. Oncol Rep 37: 903-912, 2017.

16. Zhang L, Zhang W, Li Y, Alvarez A, Li Z, Wang Y, Song L, Lv D, Nakano I, Hu B, et al: SHP-2-upregulated ZEB1 is important for PDGFRalpha-driven glioma epithelial-mesenchymal transition and invasion in mice and humans. Oncogene 35: 5641-5652, 2016.

17. Bustin SA, Benes V, Garson JA, Hellemans J, Huggett J, Kubista M, Mueller R, Nolan T, Pfaffl MW, Shipley GL, et al: The MIQE guidelines: Minimum information for publication of quantitative real-time PCR experiments. Clin Chem 55: 611-622, 2009.

18. Li X, Zhang G, Wang Y, Elgehama A, Sun Y, Li L, Gu Y, Guo W and Xu Q: Loss of periplakin expression is associated with the tumorigenesis of colorectal carcinoma. Biomed Pharmacother 87 366-374, 2017.

19. Li Y, Hu Y, Liu C, Wang Q, Han X, Han Y, Xie XS, Chen XH, Li X, Siegel ER, et al: Human fibulin-3 protein variant expresses anti-cancer effects in the malignant glioma extracellular compartment in intracranial xenograft models. Oncotarget 8: 106311-106323, 2017.

20. Clingerman KJ and Summers L: Validation of a body condition scoring system in rhesus macaques (Macaca mulatta): inter- and intrarater variability. J Am Assoc Lab Anim Sci 51: 31-36, 2012.

21. Deng J, Wang L, Chen H, Hao J, Ni J, Chang L, Duan W, Graham P and Li Y: Targeting epithelial-mesenchymal transition and cancer stem cells for chemoresistant ovarian cancer. Oncotarget 7: 55771-55788, 2016.

22. Buonato JM and Lazzara MJ: ERK1/2 blockade prevents epithelial-mesenchymal transition in lung cancer cells and promotes their sensitivity to EGFR inhibition. Cancer Res 74: 309-319, 2014

23. Ding C, Tang W, Fan X, Wang X, Wu H, Xu H, Xu W, Gao W and Wu G: Overexpression of PEAK1 contributes to epithelial-mesenchymal transition and tumor metastasis in lung cancer through modulating ERK1/2 and JAK2 signaling. Cell Death Dis 9: 802, 2018.

24. Brown JS and Jackson SP: Ubiquitylation, neddylation and the DNA damage response. Open Biol 5: 150018, 2015.

25. Han D, Liang J, Lu Y, Xu L, Miao S, Lu LY, Song W and Wang L: Ubiquitylation of Rad51d mediated by E3 ligase Rnf138 promotes the homologous recombination repair pathway. PLoS One 11: e0155476, 2016.

26. Yang B, Qin J, Nie Y, Li Y and Chen Q: Brain-derived neurotrophic factor propeptide inhibits proliferation and induces apoptosis in C6 glioma cells. Neuroreport 28: 726-730, 2017.

27. Wang XQ, Bai HM, Li ST, Sun H, Min LZ, Tao BB, Zhong J and Li B: Knockdown of HDAC1 expression suppresses invasion and induces apoptosis in glioma cells. Oncotarget 8: 48027-48040, 2017.

28. Hou M, Cheng Z, Shen H, He S, Li Y, Pan Y, Feng C, Chen X, Zhang Y, Lin M, et al: High expression of CTHRC1 promotes EMT of epithelial ovarian cancer (EOC) and is associated with poor prognosis. Oncotarget 6: 35813-35829, 2015.
29. Jayachandran A, Dhungel B and Steel JC: Epithelial-to-mesenchymal plasticity of cancer stem cells: Therapeutic targets in hepatocellular carcinoma. J Hematol Oncol 9: 74, 2016.

30. Krebs AM, Mitschke J, Lasierra Losada M, Schmalhofer O, Boerries M, Busch H, Boettcher M, Mougiakakos D, Reichardt W, Bronsert P, et al: The EMT-activator Zeb1 is a key factor for cell plasticity and promotes metastasis in pancreatic cancer. Nat Cell Biol 19: 518-529, 2017.

31. Pietilä M, Ivaska J and Mani SA: Whom to blame for metastasis, the epithelial-mesenchymal transition or the tumor microenvironment? Cancer Lett 380: 359-368, 2016.

32. De Craene B and Berx G: Regulatory networks defining EMT during cancer initiation and progression. Nat Rev Cancer 13: 97-110, 2013

33. Micalizzi DS, Farabaugh SM and Ford HL: Epithelial-mesenchymal transition in cancer: Parallels between normal development and tumor progression. J Mammary Gland Biol Neoplasia 15: 117-134, 2010.

34. Vivanco I and Sawyers CL: The phosphatidylinositol 3-Kinase AKT pathway in human cancer. Nat Rev Cancer 2: 489-501, 2002.

35. Zeng Z, Leng T, Feng X, Sun H, Inoue K, Zhu L and Xiong ZG: Silencing TRPM7 in mouse cortical astrocytes impairs cell proliferation and migration via ERK and JNK signaling pathways. PLoS One 10: e0119912, 2015.

36. Heigener DF, Gandara DR and Reck M: Targeting of MEK in lung cancer therapeutics. Lancet Respir Med 3: 319-327, 2015.

37. Liu Z, Dai H, Jia G, Li Y, Liu X and Ren W: Insufficient radiofrequency ablation promotes human hepatoma SMMC7721 cell proliferation by stimulating vascular endothelial growth factor overexpression. Oncol Lett 9: 1893-1896, 2015.

38. Dong F, Tian H, Yan S, Li L, Dong X, Wang F, Li J, Li C, Cao Z, Liu X and Liu J: Dihydroartemisinin inhibits endothelial cell proliferation through the suppression of the ERK signaling pathway. Int J Mol Med 35: 1381-1387, 2015.

39. Zhang D, Lu C and Ai H: Rab5a is overexpressed in oral cancer and promotes invasion through ERK/MMP signaling. Mol Med Rep 16: 4569-4576, 2017.

40. Morishita Y, Ookawara S, Hirahara I, Muto S and Nagata D: HIF-1 $\alpha$ mediates Hypoxia-induced epithelial-mesenchymal transition in peritoneal mesothelial cells. Ren Fail 38: 282-289, 2016.

41. Mori H, Yao Y, Learman BS, Kurozumi K, Ishida J, Ramakrishnan SK, Overmyer KA, Xue X, Cawthorn WP, Reid MA, et al: Induction of WNT11 by hypoxia and hypoxia-inducible factor- $1 \alpha$ regulates cell proliferation, migration and invasion. Sci Rep 6: 21520, 2016.

42. Park SY, Jang WJ, Yi EY, Jang JY, Jung Y, Jeong JW and Kim YJ: Melatonin suppresses tumor angiogenesis by inhibiting HIF-1alpha stabilization under hypoxia. J Pineal Res 48: 178-184, 2010.

This work is licensed under a Creative Commons Attribution-NonCommercial-NoDerivatives 4.0 International (CC BY-NC-ND 4.0) License. 